\title{
Fibroblasts at the Transection Site of the Injured Goldfish Optic Nerve and Their Potential Role During Retinal Axonal Regeneration
}

\author{
SABINE HIRSCH, MARY ANNE CAHILL, AND CLAUDIA A.O. STUERMER \\ Faculty of Biology, University of Konstanz, 78434 Konstanz, Germany
}

\begin{abstract}
The region at and around the site of optic nerve transection (ONS) in goldfish, topologically the equivalent of the glial scar in mammals, is reported to remain free of astrocytes over weeks, but its cellular constituents are unknown.

To learn what type of cell occupies the site of injury and thus provides support for the rapidly regenerating retinal growth cones, immunostaining experiments at the light microscopic level and electron microscopic examinations were undertaken. Between 2 and 30 days after ONS, an area up to $150 \mu \mathrm{m}$ wide at the transection site exhibits intense anti-fibronectin immunoreactivity. This site contained cells and processes with ultrastructural characteristics of fibroblasts and abundant collagen fibrils. Moreover, on fibroblast cultures derived from regenerating optic nerves, retinal axons grew to considerable density in vitro. Since fibroblasts are constituents of the interfascicular spaces and outer nerve sheath of the normal goldfish optic nerve, the present data imply that fibroblasts of either source migrate into the lesion Judging from fibronectin immunostaining they remain there during the passage of regenerating axons, and thus may provide physical and perhaps molecular support for axon growth. The fibroblasts are again restricted to interfascicular spaces after restoration of the astrocytic glia limitans around regenerated fascicles. 1995 Wiley-Liss, Inc.
\end{abstract}

Indexing terms: CNS injury, retinal ganglion cells, glial scar, mesenchymal cells, axon growth support

Whereas fish regenerate axons after transection of their optic nerve or spinal cord to full recovery of function, this capability for spontaneous and lengthy regrowth of CNS fiber tracts has been lost in mammals (Skene, 1989).

Specific proteins found on oligodendrocytes and CNS myelin in mammals and birds inhibit axon regrowth (Schwab et al., 1993). Such inhibition is not exerted by fish oligodendrocytes and fish CNS myelin (Vanselow et al., 1990; Bastmeyer et al., 1991). Moreover, astrocytes and mesenchymal cells (i.e., fibroblastic cells of the meninges) form a so-called glial scar at the lesion sites of injured CNS fiber tracts in mammals (Reier, 1986). This glial scar appears to represent a molecular and perhaps physical barrier to axon growth. In fish, however, sites of injury in the optic nerve (Gaze, 1970) and spinal cord (Sharma et al., 1993) are freely crossed by regenerating growth cones. A number of studies have analyzed the glia components after crush injury or transection of the fish optic nerve (Nona et al., 1989; Levine, 1991, 1993; Blaugrund et al., 1993). These studies agree that the site of injury remains devoid of astrocytes for at least 2 weeks after surgery. None of the proteins characteristic of normal or reactive fish astrocytes such as glial fibrillary acidic protein (GFAP) (Stafford et al., 1990), specific cytokeratins (Giordano et al., 1989), or vimentin (Maggs and Scholes, 1986) were detected in cells in and around the region where the nerve had been severed.

However, regenerating growth cones form within $2-4$ days after surgery at the eye-side (distal) portion of the optic nerve stump (Lanners and Grafstein, 1980) and have arrived in the brain-side (proximal) nerve stump by $8-12$ days (Murray, 1982; Lowenger and Levine, 1988; Paschke et al., 1992; Strobel and Stuermer, 1994). Thus, some sort of cellular or extracellular structural support is suspected to be available to the regrowing axons in this region to allow axons to cross the lesion site. Having grown across the lesion, leading growth cones contact a variety of cellular profiles (Strobel and Stuermer, 1994), whereas growth cones which follow appear to fasciculate with the leading

Accepted March 27, 1995.

Address reprint requests to C.A.O. Stuermer, Faculty of Biology, Univ, of Konstanz, D-78434 Konstanz, Germany.

Sabine Hirsch is now at Max-Planck-Institut für Entwicklungsbiologie, D-75076 Tübingen, Germany. 
axons (Easter, 1987; Strobel and Stuermer, 1994). Moreover, several growth-promoting molecules have been identified immunocytochemically (Hopkins et al., 1985; Battisti et al., 1992) or have been implied to exist in the injured goldfish optic nerve (Carbonetto et al., 1987). The identity and molecular properties of non-neuronal cells at fish optic nerve transection sites are not well defined. The site, which is the topological counterpart of the glial scar in mammals, deserves specific attention because of the striking differences in response to injury of CNS fiber tracts in mammals and fish (review: Johnson, 1993).

This study was undertaken to identify the cell types and potential substrates for regenerating retinal axons at the transection site in the goldfish optic nerve. Specifically, we investigated whether cells of mesenchymal origin, such as fibroblasts, fill the gap. This question arose from the following observations: 1) Regenerating growth cones are in membrane-to-membrane association with a fibroblast (called fibroblast-like cell, in Strobel and Stuermer, 1994) in the interfascicular area of the proximal nerve stump, suggesting that regenerating retinal ganglion cell (RGC) axons of fish may use fibroblasts as a substrate for their growth; 2) fish regenerating $\mathrm{RGC}$ axons in vitro elongate on the extracellular matrix (ECM) molecule fibronectin (Vielmetter et al., 1990) and on collagen, which fibroblasts can produce; 3) mesenchymal cells, leptomeningeal cells, or cells of typical fibroblast morphology are known to invade lesion sites of CNS fiber tracts in mammals (Reier, 1986; Reier and Houle, 1988), although they fail to support axon regrowth in warm-blooded species (Rudge and Silver, 1990; McKeon et al., 1991).

The present immunocytochemical data at the light microscopic level and electron microscopic analysis of the transection site provide evidence for the presence of fibroblasts during the period in which regenerating RGC axons cross the lesion site of the fish optic nerve. Moreover, fish RGC axons in vitro regenerate well on a substrate consisting of fibroblasts derived from the lesioned goldfish optic nerve.

Preliminary results were presented in an abstract (Hirsch et al., 1994).

\section{MATERIALS AND METHODS}

The optic nerves of goldfish (5-8 cm long) were cut or crushed under MS 222 anesthesia in compliance with animal welfare legislation and kept at $18^{\circ} \mathrm{C}$. Individual fish were killed at $2,4,6,8,10,14,30$, and 180 days after optic nerve section (ONS), and at 4,10 , and 14 days after crush. The nerves, including the transection or crush site and portions of the proximal and distal nerve, were isolated and cut into $10-\mu \mathrm{m}$ longitudinal sections on a cryostat. Sections were collected on glass slides and fixed in $100 \%$ ice-cold methanol (5 minutes), rinsed in $0.1 \mathrm{M}$ phosphate-buffered saline (PBS), postfixed in 2\% paraformaldehyde in PBS (5 minutes, room temperature), and rinsed twice in PBS. Sections were exposed to primary antibodies (see below) and then to secondary antibodies (Dianova), which were goat anti-mouse (coupled with FITC or RITC) or goat anti-rabbit antibodies (coupled with FITC or RITC), for 1.5 hours at $37^{\circ} \mathrm{C}$. Sections were coverslipped under Mowiol (Boehringer-Mannheim) and viewed and photographed in a Zeiss-Axiophot with the appropriate filter sets.

Primary antibodies and their dilutions (in PBS) were monoclonal antibody (MAB) M 501 and MAB E 21 (Paschke et al., 1992), hybridoma supernatants (1:3); MAB E 587
(Vielmetter et al., 1991), hybridoma supernatant (1:2); polyclonal anti-GFAP (Nona et al., 1989) $(1: 1,000)$, kindly provided by S. Nona (Manchester) and MAB anti-GFAP (Boehringer-Mannheim) (1:100); MAB anti-Vimentin, hybridoma supernatant (1:2), kindly provided by B. Sproll (Tübingen); MAB O4, hybridoma supernatant (Sommer and Schachner, 1981) (1:2); MAB 6D2 against fish myelin proteins IP1 and IP2 (Jeserich and Rauen, 1990), hybridoma supernatant (1:2), kindly provided by G. Jeserich (Osnabrück); MAB anti-cytokeratin pan (BoehringerMannheim; 1:10); polyclonal anti-laminin (Nos. 974 and 939 against mouse laminin fragment EIXNd and laminin complete, respectively; $1: 100$ ), kindly provided by $\mathrm{R}$. Timpl (München); polyclonal anti-fibronectin (Telios; 1:100); MAB SMI-31 (Sternberger Monoclonals Inc.; 1:1,000) and MAB anti-S 100 (Dacopatts; 1:100).

Immunoblots with polyclonal antibodies (ABs) against fibronectin were performed according to conventional methods (Towbin et al., 1979) using proteins extracted from homogenized goldfish optic nerves, which were subjected to sodium dodecyl sulfate-polyacrylamide gel electrophoresis SDS-PAGE and transferred to immobilon (Millipore Corp. Bedford, MA). Antibody binding was detected by alkaline phosphatase goat anti-rabbit secondary antibody (Promega Corp. Madison, WI) and revealed a band of the expected molecular weight of $220 \mathrm{kD}$.

\section{Electron microscopy}

Optic nerves, 8 days after ONS, were fixed overnight in $1 \%$ glutaraldehyde (Merck) in $0.15 \mathrm{M}$ cacodylate buffer or $0.1 \mathrm{M}$ phosphate buffer, postfixed in $1 \%$ osmium tetroxide in buffer ( 1 hour), rinsed, dehydrated in a graded series of alcohols, stained en bloc with $0.5 \%$ uranylacetate in $70 \%$ alcohol, and embedded in Spurr's epoxy resin. Semithin and ultrathin sections were cut on a Reichert OM U3 ultramicrotome. Semithin sections were stained with an aqueous solution of azure blue and methylene blue (Richardson et al., 1960). Ultrathin sections were counterstained with lead citrate (Reynolds, 1963) and viewed and photographed with a Zeiss EM 900 transmission electron microscope.

\section{Cell culture}

Our optic nerve/tract glia cultures usually give rise to network-like carpets of oligodendrocytes with clusters of astrocytes interspersed among them (Bastmeyer et al., 1993). Fibroblasts are rare. To obtain cultures with an increased number of fibroblasts, optic nerves 14-21 days after ONS were divided into small pieces, transferred to a polylysine/laminin-coated coverslip, and kept sandwiched between two coverslips in F 12 medium (Gibco) for several days without exchanging the medium. Cultures were examined microscopically and those rich in cells with fibroblast morphology (Bastmeyer et al., 1993, 1994) were selected. Segments of goldfish retinae $200 \mu \mathrm{m}$ wide were prepared (Vielmetter et al., 1990; Bastmeyer et al., 1991) and explanted onto the cell carpet. After 2 days the cultures were fixed and immunostained with MAB SM-31 as described above.

\section{RESULTS Normal optic nerves}

To understand the formation of the scar at the site of goldfish optic nerve transection and to reveal the origin of the fibroblasts assembled therein, normal nerves were 

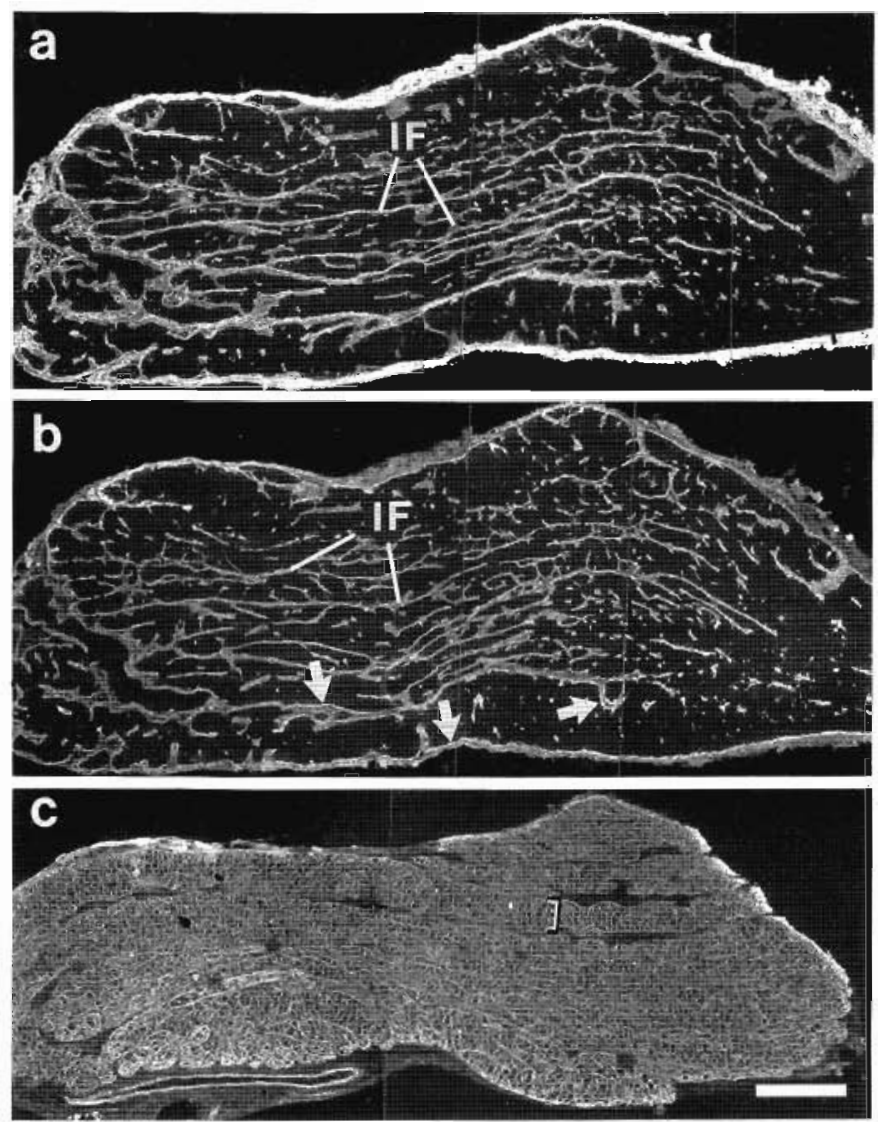

Fig. 1. Longitudinal sections through a normal goldfish optic nerve immunostained with antibodies against fibronectin (FN) (a), laminin (b), and cytokeratins (c). a: FN immunolabeling is associated with the outer nerve sheath and the interfascicular spaces (IF). b: Section adjacent to that shown in a. The interfascicular spaces (IF) exhibit some laminin immunoreactivity. Staining is brightest on the basal laminae (arrows). c: A nonadjacent section of the same nerve demonstrating the presence of astrocytes through their reaction to anti-cytokeratins. Anti-cytokeratins stain the glia limitans and astrocytic processes within axon fascicles (bracket). Scale bar $=200 \mu \mathrm{m}$. In this and subsequent figures the eye-side (distal) portion is to the left, the brain-side (proximal) portion to the right. analyzed using anti-fibronectin (FN) antibodies and electron microscopy.

The optic nerve of goldfish is partitioned into fascicles, each surrounded by a glia limitans consisting of processes of astrocytes and a basal lamina (Maggs and Scholes, 1990). The interfascicular spaces, as well as the outer nerve sheath, are brightly labeled by fibronectin antibodies (Fig. 1a). Laminin antibodies gave a similar but not identical staining pattern (Fig. 1b), which often appeared brighter on what may represent the basal lamina than in the interfascicular spaces proper. Anti-cytokeratin antibodies (Markl and Franke, 1988; Giordano et al., 1989, 1990) and antivimentin (Maggs and Scholes, 1986), both markers for astrocytes in normal fish optic nerves, delineated the fascicle borders and the astrocytic partitions (Maggs and Scholes, 1990) therein (Fig. 1c) but did not stain the interfascicular, FN-positive spaces.

When the interfascicular area and outer nerve sheath were examined electron microscopically, one of the most conspicuous elements present were fibroblasts. In the interfascicular spaces, long fibroblast processes and bundles of collagen fibrils ran parallel to the glia limitans covering the fascicles (Fig. 2). This organization is reminiscent of the perineural area of peripheral nerves (Scherer and Easter, 1984; Peters et al., 1991). Fibroblasts and collagen fibrils were also found in the outer nerve sheath, which resembles the epineurium of peripheral nerves (Scherer and Easter, 1984; Peters et al., 1991). Granulocytes were frequently seen in both areas (Murray, 1982; Easter, 1987; Strobel and Stuermer, 1994). The presence of fibroblasts in interfascicular spaces suggests that they are the source of the FNimmunoreactivity in the fish optic nerve.

\section{Transected optic nerves}

Except at the site of optic nerve transection, the lesioned nerve retains its gross organization of fascicles and interfascicular areas (Murray, 1982; Strobel and Stuermer, 1994) despite the degeneration of the axons and myelin sheath and the structural changes associated with it. Likewise, the pattern of $\mathrm{FN}$-immunoreactivity and anti-laminin labeling of the interfascicular spaces and outer nerve sheath was preserved (Figs. 3,6). Major changes, however, occurred at the site of nerve transection, where a scar-like structure develops.

The transection site is initially only a gap between the nerve stumps. However, a narrow rim of fibronectin immunoreactivity where the proximal and distal nerve stumps face the gap was already seen at 2 days after transection. By 4 days after ONS, the gap had filled with FN-immunoreac- 


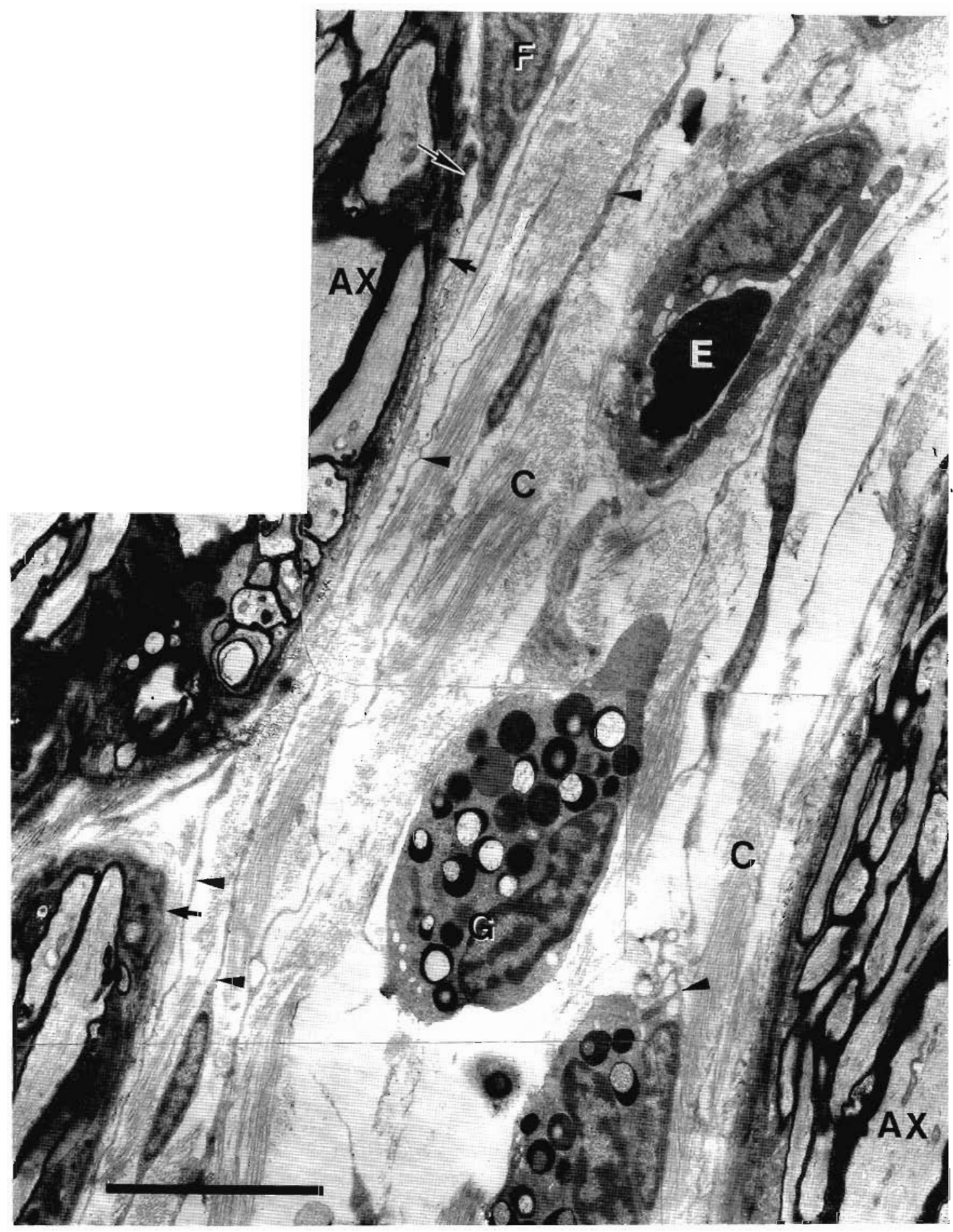

Fig. 2. Electron micrograph of the interfascicular space in a normal optic nerve. It contains collagen fibrils (C) and long processes of fibroblasts (arrowheads) (F) which are separated from the myelinated

tive cells (Fig. 3a). FN-immunoreactivity occupied an increasingly wider space at the cut site from 4 to 14 days after ONS (Fig. 3b,c). To investigate whether the appearance of FN-immunoreactivity is a phenomenon specific for sectioned nerves, nerves which were crushed instead of cut were subjected to $\mathrm{FN}$-immunostaining at 4,10 , and 14 days axons ( $\mathrm{AX}$ ) of the fascicle by a basal lamina (arrow) and astrocytic processes which form the glia limitans. G, granulocyte; $E$, erythrocyte in a capillary. Scale bar $=5 \mu \mathrm{m}$.

after surgery. A similar $\mathrm{FN}$-immunoreactive region up to $150 \mu \mathrm{m}$ wide was also found in these preparations, suggesting that both types of nerve injury lead to the assembly of FN-immunoreactive cells at the site of lesion. At 30 days after ONS, when most regenerating axons have crossed the lesion and re-occupied the entire tectum (Stuermer and 

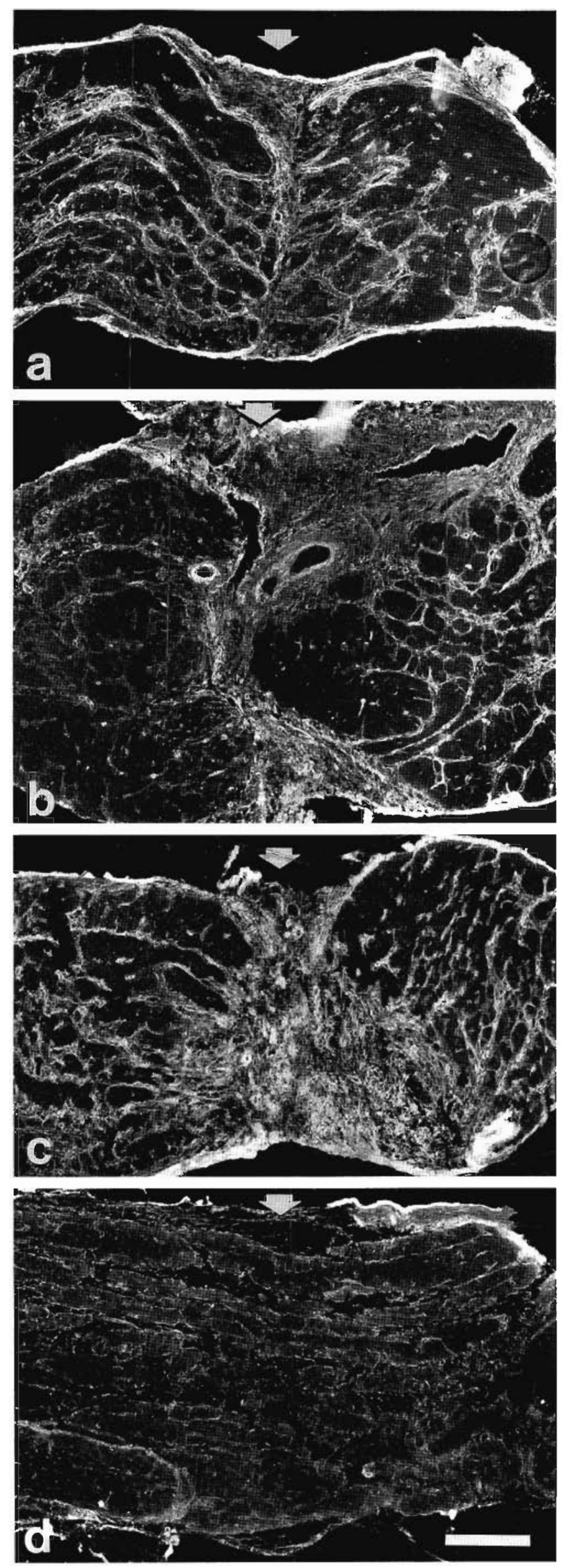

Easter, 1984), FN-immunoreactive processes at the transection site acquired various orientations which merged with the more orderly interfascicular $\mathrm{FN}$-immunoreactive pattern in the proximal nerve stump. The transection site was no longer seen at 180 days after ONS when axon fascicles and interfascicular spaces had reformed (Fig. 3d).

To confirm that regenerating axons pass through the transection site during and after the time of $\mathrm{FN}$-positive scar development, sections of nerves 6 and 8 days after ONS were labeled by MAB E 587 against an L 1-like growthassociated cell surface protein (Vielmetter et al., 1991) which selectively recognizes regenerating axons. Small fascicles of $\mathrm{E}$ 587-positive axons were seen in the FNpositive scar region (Fig. 4). Anti-cytokeratin- and GFAPpositive glial cells were absent from the transection region until 10 days after ONS. By 14 days after ONS, some GFAP-positive (and anti-cytokeratin-immunoreactive) processes had entered the transection site (Fig. 5a), where the proximal and distal nerve stumps also show the presence of the astrocytic marker

Furthermore, markers for oligodendrocytes (MAB antiGal-C and MABs 6D2, O4) failed to stain this region (Fig. 5 b) but labeled myelin and myelin debris in fascicles in the distal and proximal nerve stumps. There was no antilaminin immunoreactivity in the transection site until 10 days after ONS (Fig. 6a). Some laminin staining appeared at 14 days along with the reappearance of GFAP (Fig. 6b).

It has been reported (Nona et al., 1989; Levine, 1989; Blaugrund et al., 1993) that astrocytes are absent from the lesion site after optic nerve crush. The same appears to be true of optic nerve cut. We found no immunoreactivity indicative of astrocytes during the time that regenerating axons arrive at and cross through the lesion in our preparations after optic nerve cut. Nor did we find any evidence of oligodendrocytes.

The presence of fibroblasts at the transection site was confirmed with electron microscopy (Fig. 7a,b). Besides various blood-derived cells (erythrocytes, monocytes, plasma cells, granulocytes) (Rhodin, 1977) microglial, phagocytizing cells and large extracellular spaces were characteristic. Consistent with descriptions of fibroblasts in mammalian (Peters et al., 1991) and fish peripheral nerves (Scherer and Easter, 1984) fibroblasts at the transection site of the fish optic nerve (Fig. 7a,b) had nuclei with indentations and patchy chromatin along the margin and within the nucleus. These fibroblasts exhibited characteristic rER cisternae, which were often arranged in parallel rows (Strobel and Stuermer, 1994), as well as numerous free ribosomes and microfilaments (Peters et al., 1991). They typically give rise to long processes which often have electron light caveolae (Scherer and Easter, 1984). The fibroblasts and their processes were associated with prominent bundles of collagen fibrils. Cells with characteristics of astrocytes (dense strands of microfilaments, prominent desmosomes) (Maggs and Scholes, 1986, 1990; Strobel and Stuermer, 1994) were not seen.

Bundles of regenerating axons consisting of a few or dozens of profiles (Murray, 1982) were noted among the

Fig. 3. Longitudinal sections of optic nerves after optic nerve transection (ONS) and immunostaining with fibronectin antibodies. An accumulation of FN-immunoreactive structures at the transection site (arrow) is evident at 4, 8, and 14 days after ONS (in $\mathbf{a}, \mathbf{b}, \mathbf{c}$, respectively), but has disappeared by 180 days (d) when the organization of fascicles and interfascicular spaces is restored. Scale bar $=200 \mu \mathrm{m}$. 

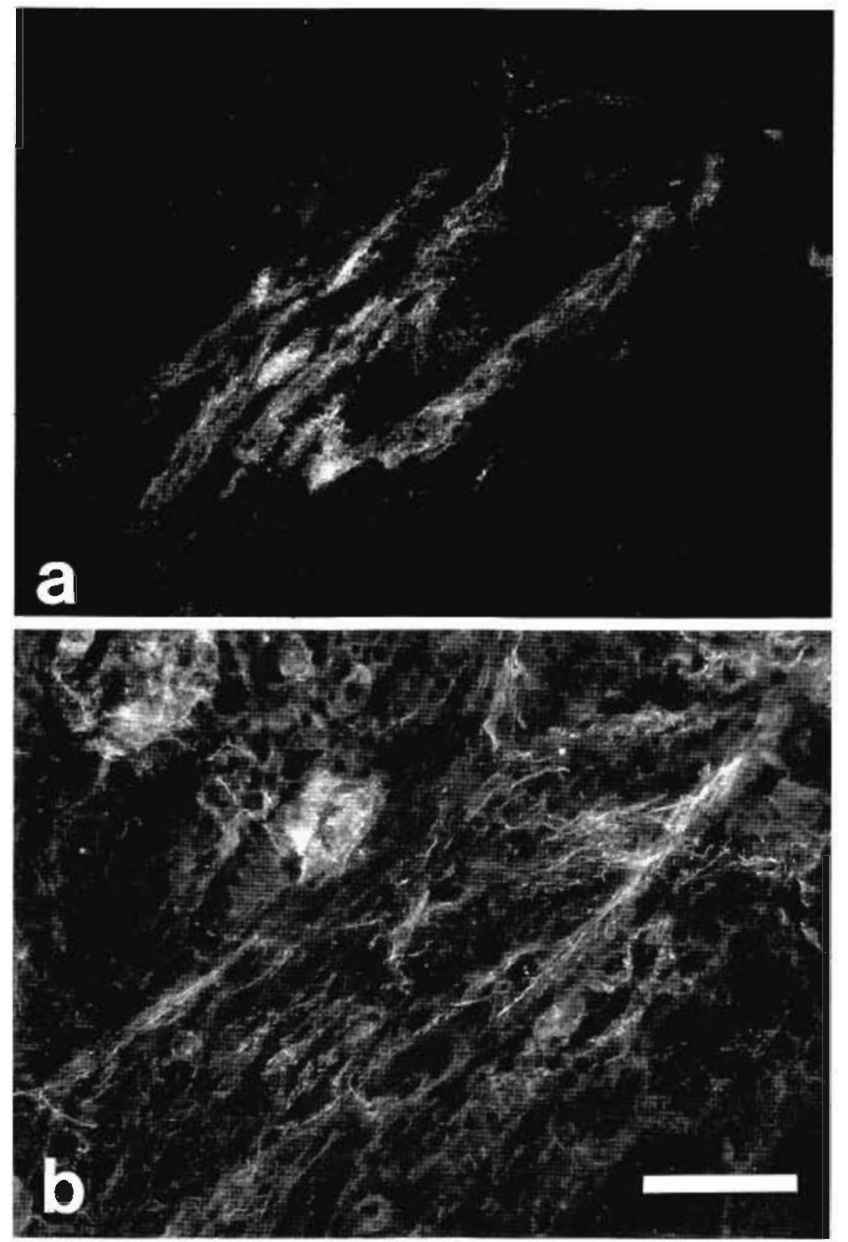

Fig. 4. Higher magnification of the transection site of a nerve 8 days after ONS, double stained with MAB E 587 (a) and anti-fibronectin antibodies (b). E 587-positive regenerating axons are coursing among the FN-positive processes. Scale bar $=50 \mu \mathrm{m}$.

various cell types in the transection site. Axonal profiles, identified by their content of microtubules and neurofilaments, as well as putative growth cones (Easter et al., 1984) of axons in larger bundles often occurred in direct contact with fibroblast processes and collagen (Figs. 8, 9).

These observations support the notion that regenerating retinal axons grow through the assembly of cells of the lesion site and provide evidence that fibroblasts and their ECM products may serve as substrates for axonal growth. Interestingly, some bundles of ten and more axons were partially surrounded by electron light cell processes (Fig. $9 b$ ), suggesting that axons quickly become separated from the cell assembly of the lesion site once they have crossed the area. The type of cell which subserves this function was not unequivocally identified, but its content of rER, polyribosomes, typical mitochondria, and the collagen fibrils apposed to it is indicative of fibroblast processes.

\section{Axon growth on fibroblasts in vitro}

To determine whether fibroblasts from the regenerating optic nerve support the growth of regenerating retinal axons, optic nerve cells were raised in vitro by a procedure modified from that described previously (Bastmeyer et al.,
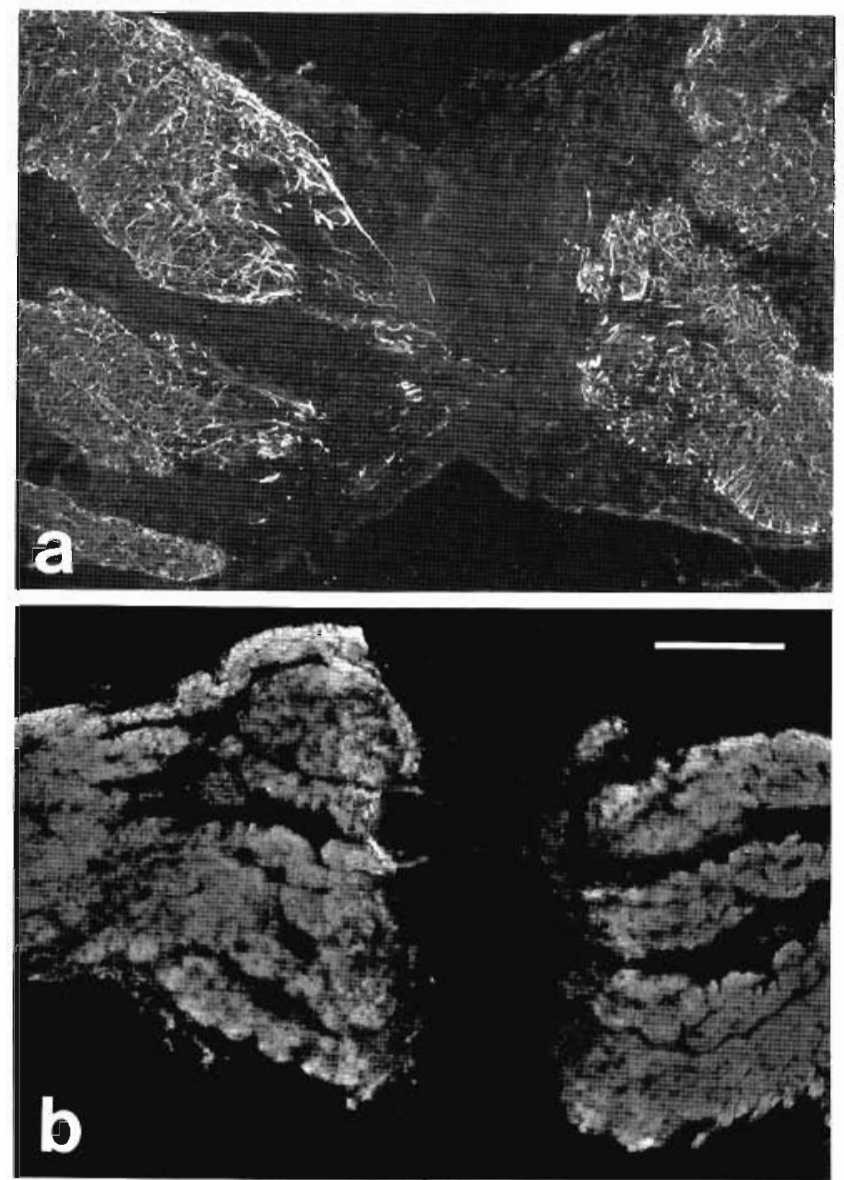

Fig. 5 . Longitudinal sections of the optic nerve transection site 14 days after ONS immunostained with anti-g]ial fibrillary acidic protein (GFAP) (a) and with MAB 6D2 (b). a: Astrocytes, identified by their anti-GFAP immunoreactivity, have begun to repopulate the transection site. b: MAB 6D2 immunoreactivity, indicative of myelin-forming cells, is not seen within this region. Scale bar $=200 \mu \mathrm{m}$.

1991, 1993; and Materials and Methods). The small pieces of optic nerves explanted on suitable substrates (Bastmeyer et al., 1994; and Materials and Methods) give rise (through emigration and division of cells) to carpets consisting of a mixture of cells with variable proportions of fibroblasts and oligodendrocytes. Of 20 cocultures, two consisted almost exclusively of fibroblasts, and 18 were a mixture of oligodendrocytes and fibroblasts. Astrocytes appeared to be rare in these cultures. Fibroblasts were, as reported earlier (Bastmeyer et al., 1994) negative with respect to MABs O4, 6D2, and GFAP but FN-immunoreactive (Fig. 10a) and positive to MAB E 21 at cell contact sites.

Retinal explants placed on cultures consisting almost exclusively of fibroblasts extended axons within 24 hours and grew to considerable density over the next 24 hours, at which time they were visualized by the anti-neurofilament antibody SM-I (Fig. 10b). In cultures with oligodendrocytes and fibroblasts, axons crossed both cell types without exhibiting a notable preference for either and reached axonal densities comparable to those seen in Figure 10b. However, with optic nerve/tract cultures (Bastmeyer et al., 1993), in which extended carpets of oligodendrocytes had formed, the density of axons extending from explants was often significantly higher than in the present cultures. It 

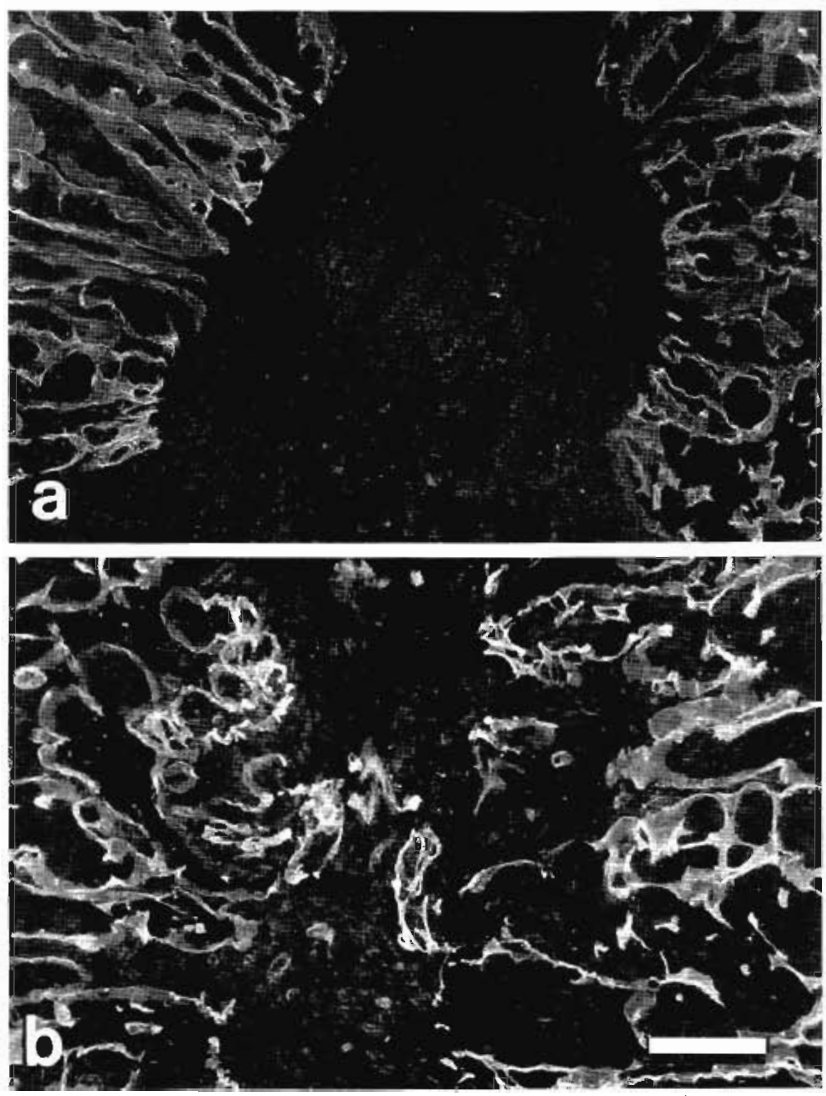

Fig. 6. Longitudinal section of the transection site. Lamininimmunoreactive structures are absent from the transection site at 6 days after ONS (a), but some are noted in this region 14 days after ONS (b). Scale bar $=100 \mu \mathrm{m}$

was impossible to count axons because of their abundance. These findings suggest that oligodendrocyte cultures derived from optic nerve/tract (Bastmeyer et al., 1993) may be a better substrate than optic nerve fibroblasts or fibroblast/oligodendrocyte mixtures. Nevertheless, fibroblasts derived from optic nerve are capable of supporting axon growth.

\section{DISCUSSION}

This study has identified fibroblasts as an abundant cell type in the lesion site after optic nerve transection. They occupy this region when regenerating growth cones migrate through it. The fibroblasts most likely derive from the interfascicular spaces and outer nerve sheath, where they are found in normal goldfish optic nerves. Moreover, fibroblasts of regenerating optic nerves allow retinal axonal regeneration in vitro and thus are candidate substrates for the growth of regenerating growth cones across the lesion site.

The present results provide evidence as to which nonneuronal cells fill the gap at the lesion site at the time crucial for axon growth from the distal into the proximal nerve stump. They also reveal a further difference between the lesion site of fish and the glia scar which forms in mammals. Our findings suggest that fibroblasts and/or their extracellular matrix products might represent permissive substrates for the growth of regenerating growth cones across the lesion site. Several observations support this view: regenerating fish retinal axons grow on fibroblasts in vitro; they have been demonstrated to elongate on fibronectin substrates (Vielmetter et al., 1990) and on collagen (unpublished observation); profiles of regenerating axons were seen in direct contact with fibroblast processes (here and Strobel and Stuermer, 1994) and collagen; the other cell types at the transection site are microglial cells and phagocytes or other cells of hematogeneous origin and are perhaps less likely substrates for axon growth, although specific molecules produced by macrophages, microglia, and monocytes may also contribute directly or indirectly to axonal regeneration (i.e., Nathan, 1987; Guilian et al., 1993; Chamak et al., 1994).

Judged from the location of growth cones in vivo, the preferred substrate for regenerating axons is other axons (Murray, 1982; Easter, 1987; Strobel and Stuermer, 1994). Moreover, tissue culture experiments indicate that oligodendrocytes derived from fish optic nerve/tract support retinal axonal regeneration to a greater extent (Bastmeyer et al., 1993) than optic nerve-derived fibroblasts or fibroblast/ oligodendrocyte mixtures. Fish oligodendrocytes in 'culture are motile and highly growth-supportive for regenerating axons (Bastmeyer et al., 1993) and were initially suspected to migrate into the lesion site to promote axonal regeneration. However, immunocytochemical and electron microscopic experiments have not identified oligodendrocytes during the first 14 days within the lesion site. Also, we have not been able to detect Schwann cells, which exhibit S-100 immunoreactivity (Nona et al., 1994) and which are thought to invade the lesioned nerve after crush injury. They were hardly detected after nerve cut (M. Bastmeyer and S. Nona, personal communication).

Thus, fibroblasts and their ECM products may allow retinal' axonal regeneration in vivo although they may not represent the optimal substrate. Additional molecular components may further contribute to the supportiveness of the optic nerve transection site (see below).

Astrocytes are unlikely to be a guide for axons across the lesion site. Consistent with previous findings on crushed optic nerves (Levine, 1991), astrocytes remain absent from the lesion site in our preparations for roughly 10 days, whereas they represent normal and persisting components of the proximal and distal nerve stumps (Maggs and Scholes, 1986). Fish astrocytes can be identified by antibodies against specific forms of cytokeratins (Giordano et al., 1989, 1990; Levine, 1991) and vimentin (Maggs and Scholes, 1986), and by anti-GFAP, particularly after lesioning the optic nerve (Stafford et al., 1990; Levine, 1991). At the ultrastructural level, astrocytes are recognized in particular by their content of intermediate filaments and their striking desmosomes (Maggs and Scholes, 1990; Strobel and Stuermer, 1994). The absence of these characteristics from cells at the lesion site proper suggests that cells therein, and in particular those in association with regenerating axons, may be glia precursors (Blaugrund et al., 1993) at the most. The lack of markers for fish glial precursors prevents direct testing of this. However, the proximity of collagen to cells with typical fibroblast ultrastructure (Scherer and Easter, 1984; Peters et al., 1991) indicates the presence of fibroblasts, which in our preparations at 8 days after optic nerve section are, aside from hematogeneous and phagocytizing cells, the predominant cell type.

Fibroblasts are normal constituents of the interfascicular areas and the outer sheath of the goldfish optic nerve. This 


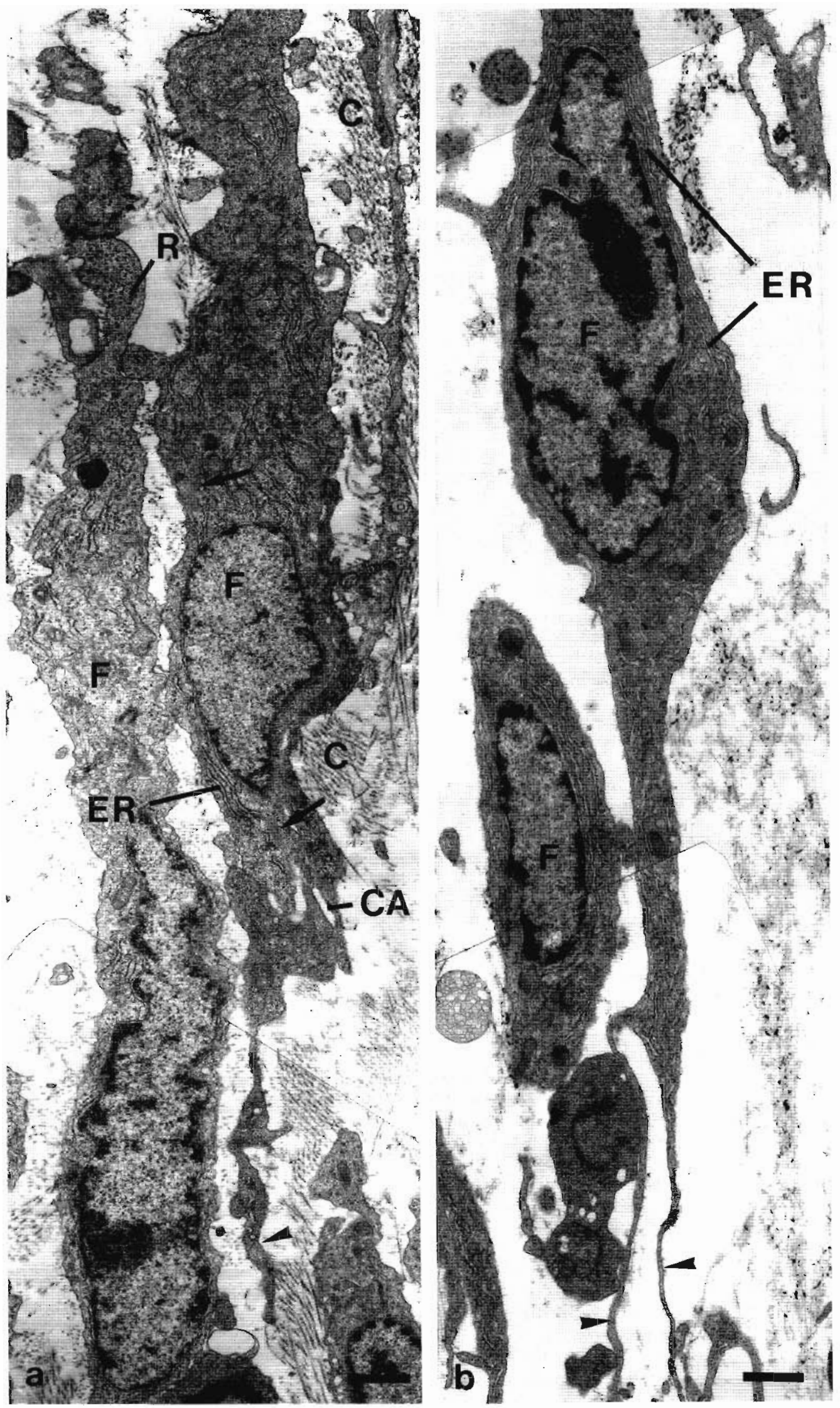

Figure 7 


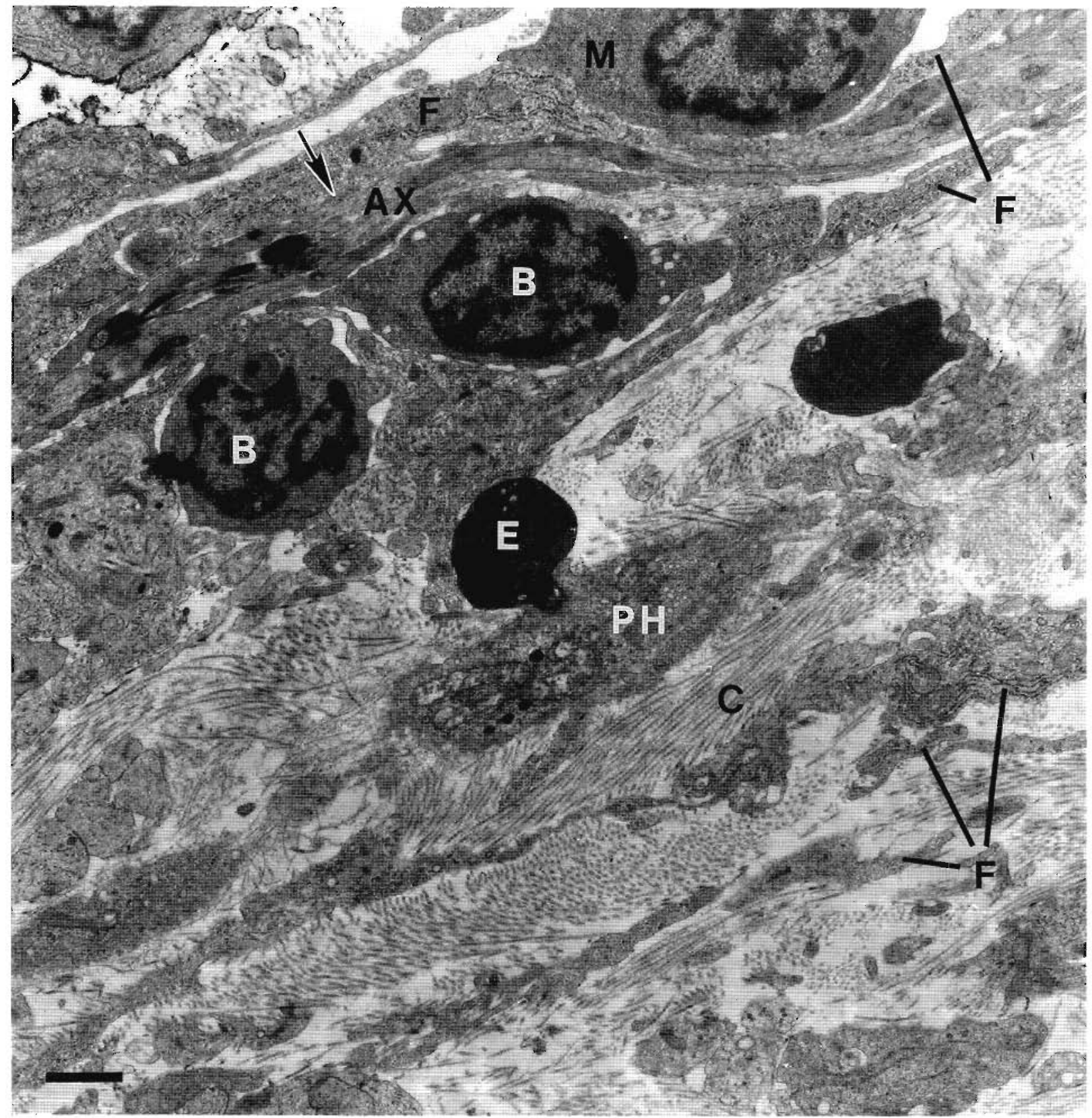

Fig. 8. Electron micrograph of the transection site of a nerve at 8 days after ONS. Typically found in this region are fibroblasts and their processes $(\mathrm{F})$, collagen fibrils $(\mathrm{C})$, microglial cells $(\mathrm{M})$, phagocytes $(\mathrm{PH})$, blood-derived cells (B, either plasma cells or monocytes), erythrocytes

(E), and regenerating axons (AX), identified by their content of microtubules and neurofilaments (see Fig. 9). Note the close association of a small bundle of regenerating axons with a process of a fibroblast (arrow). Scale bar $=1 \mu \mathrm{m}$.

is demonstrated in the present study by FN-immunostaining and electron microscopy. Our present observations are consistent with the view that fibroblasts are activated to

Fig. 7. Transverse (a) and longitudinal (b) sections through the lesion site 8 days after ONS. The fibroblasts shown here $(\mathrm{F})$ exhibit abundant rough endoplasmic reticulum (ER) in typical parallel array (arrowheads), caveolae (CA), and long, thin processes, whose continuity with the cell body can be seen. C, collagen; R, polyribosomes. Arrows: microfilaments. Scale bar $=1 \mu \mathrm{m}$. migrate and assemble in this area by an injury-associated release of factors (review: Nathan, 1987) much as in other wound areas.

Fibronectin and collagen, both produced by fibroblasts, may represent some of the growth-promoting molecules in and around the lesion site, but they are probably not the only ones. An increase in laminin has been reported (Hopkins et al., 1985; Battisti et al., 1992) throughout the regenerating goldfish optic nerve including the crush site (Battisti et al., 1992) where cells (which were not specified by the authors) had accumulated. These authors proposed 

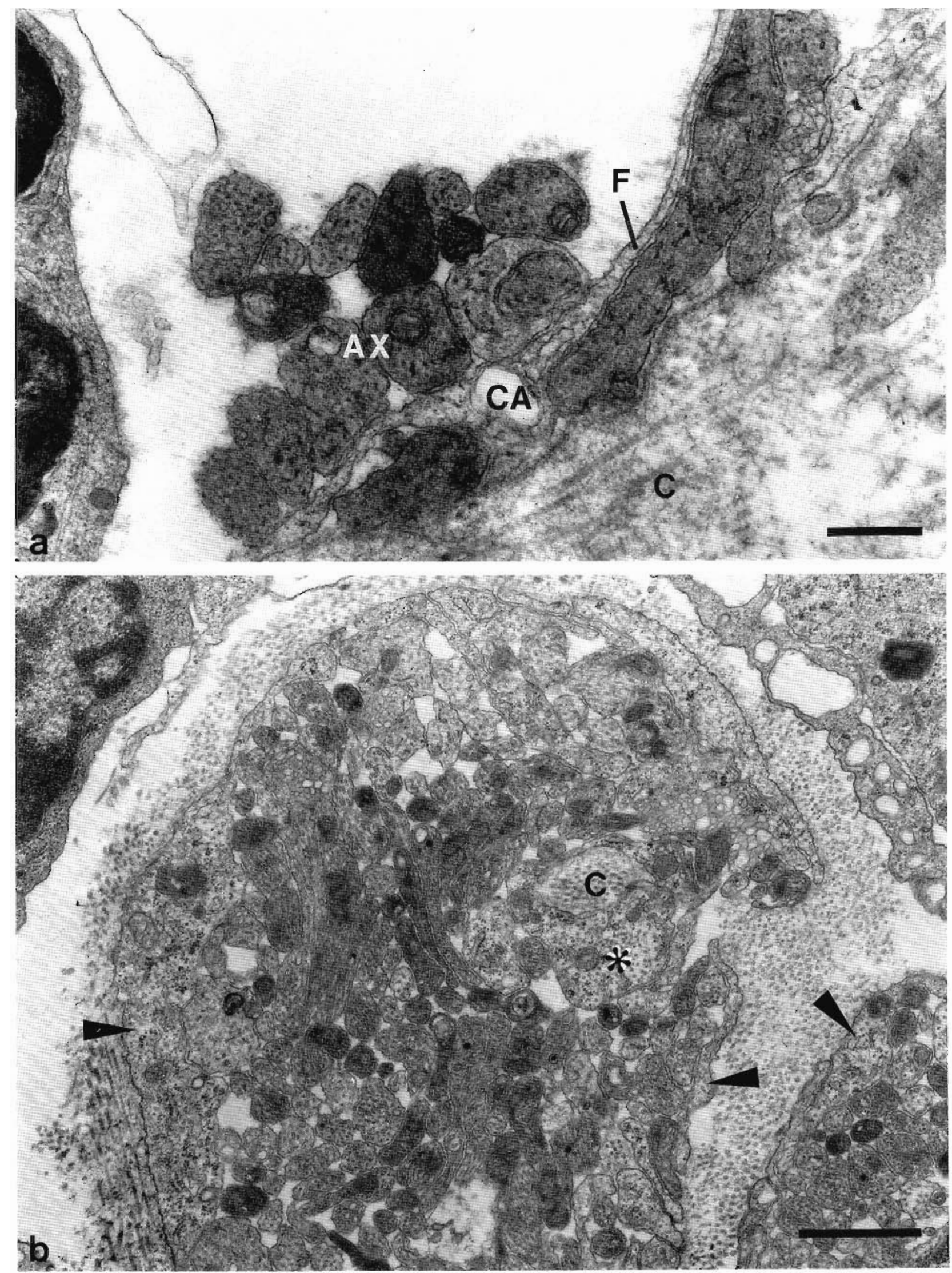

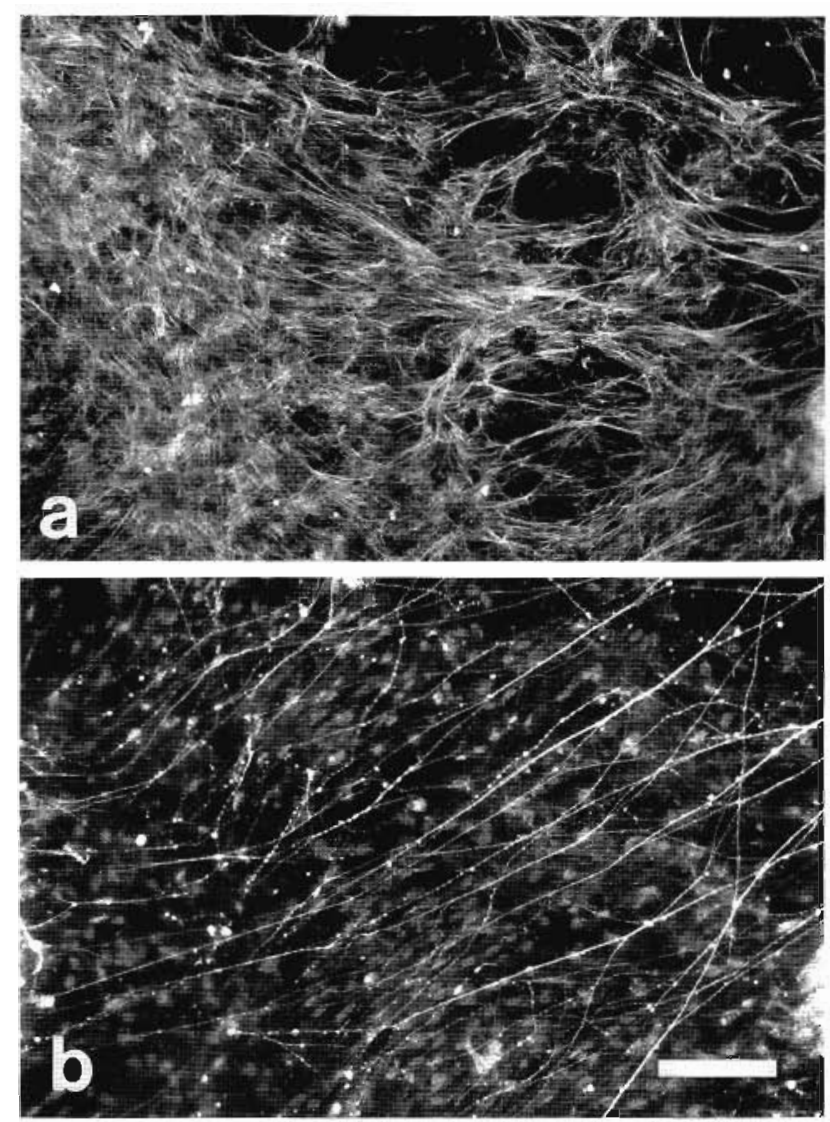

Fig. 10. A co-culture of fibroblasts and a retinal explant. a: Fibroblasts visualized by anti-fibronectin immunostaining. b: Same field as in a showing axons labeled by the anti-neurofilament antibody SM-I growing on the surface of the fibroblasts. Scale bar $=100 \mu \mathrm{m}$.

that astrocytes increase synthesis or decrease turnover of laminin in response to nerve crush and that the increased level of laminin may contribute to axonal regeneration. The laminin antibodies available to us labeled the glia limitans of the fascicles in the proximal and distal nerve portions brightly, labeled the interfascicular spaces more diffusely, and did not label the lesion site itself between 1 and 10 days after transection. Laminin immunoreactivity showed up at 14 days after ONS concurrent with the appearance of the first GFAP-positive astrocytes. Our observations suggest that laminin might not be produced by the fibroblasts, at least not by those in the scar region. Alternatively, fibroblasts in the transection site may express a laminin isoform which is not recognized by the antibodies used here.

An increase in chondroitin sulfate proteoglycan immunoreactivity was noted (Battisti et al., 1992) at the crush site between 1 and 3 weeks after crush. Outside of this region and in normal nerves it is associated with what we interpret as the interfascicular spaces. Thus, chondroitin sulfate

Fig. 9. a: Axon profiles $(\mathrm{AX})$ in association with a process of a fibroblast $(\mathrm{F})$ within the transection site. $\mathrm{C}$, collagen; $\mathrm{CA}$, caveola. Scale bar $=0.5 \mu \mathrm{m}$. b: Axon bundles partially enclosed by electron light cellular processes (arrowheads). A larger axonal profile, a putative growth cone (*), is seen in contact with collagen fibrils (C). Scale bar $=1 \mu \mathrm{m}$. proteoglycan may be one of the other molecules produced by fibroblasts.

In fish, fibroblasts assemble at the optic nerve transection site much as fibroblasts or leptomeningeal cells participate in scar formation in the mammalian CNS (Reier, 1986; Rudge and Silver, 1990). One major difference is the predominance of astrocytes in mammalian scars. In fact, besides oligodendrocytes and myelin, reactive astrocytes of such scars are considered to be one of the major impediments to axonal regeneration in the CNS of mammals (reviewed in Reier, 1986; Luizzi and Lasek, 1987; Reier and Houle, 1988; Bovolenta et al., 1992). A recent study shows that astrocytes obtained from adult rat optic nerves were unfavorable substrates for both fish and rat retinal ganglion cells (Baehr et al., 1995). In cultures in which fish astrocytes formed clusters among carpets of fish oligodendrocytes, these astrocytes were avoided by both fish and rat retinal axons which preferred to elongate on oligodendrocytes (Bastmeyer et al., 1993). A comparison of retinal axonal growth on fish fibroblasts and astrocytes was impossible because astrocytes were extremely rare in our optic nerve cultures.

When cells of a scar in the mammalian hippocampus were offered as substrate to growing axons in vitro, its reactive astrocytes--but more so its fibroblasts-reduced the rate of axon growth (Rudge and Silver, 1990), indicating that both of these cell types express molecules unfavorable for mammalian axon growth.

It is unknown at present whether the difference in the ability to grow through the lesioned fish optic nerve or mammalian CNS glial scar is due to different molecules made by fibroblasts and other non-neuronal cells or to differences in the growth cones themselves. It has become clear that regenerating fish axons are capable of reexpressing several growth-associated cell surface proteins (Bastmeyer et al., 1990; Vielmetter et al., 1991; Paschke et al., 1992; review: Stuermer et al., 1992), and it is likely that they express the relevant receptors for several ECM molecules although this has not been shown directly. It is clear that fish axons accept a variety of substrates for their regenerative growth in vitro (Vielmetter et al., 1990) and in vivo (Strobel and Stuermer, 1994). Their successful growth on fibroblasts in vitro and their association with this cell type in vivo supports this notion.

Another important difference from the situation in mammals is the disappearance of the "scar" in fish, which occurs after the axons have rebuilt connections with the tectum. The temporal and spatial distribution of fibroblasts, astrocytes, and axons in the transected nerve suggests that astrocytes re-enter the lesion site (Levine, 1991, 1993; Blaugrund et al., 1993) after the axons have grown through. This gives rise to speculation that they may require the presence of axons to enter this territory. With time, astrocytes at the lesion site re-form a glia limitans around regenerated axon fascicles. The present immunocytochemical results suggest that fibroblasts are then excluded from the newly created axon/glia domains and are again restricted to the interfascicular spaces (Fig. 3d). Whether astrocytes and fibroblasts mutually exclude each other from their specific territories requires further experiments.

We emphasize here the early appearance of fibroblasts at the optic nerve transection site since they have not, to our knowledge, been recognized as constituents in this region nor have they been considered as potential guides for regenerating axons across the lesion. The assembly of 
fibroblasts at the lesion site when axons cross and their later restriction to interfascicular spaces after axons have passed is complementary to the initial absence and subsequent reappearance of astrocytes at the site (Levine, 1991, 1993; Blaugrund et al., 1993). Although still insufficiently understood, the interaction of neuronal, mesenchymal, and glial cells may contribute to the success of axonal regeneration in the fish optic nerve and the restoration of the nerve's normal organization.

Other cell types at and around the lesion site, such as microglia (David et al., 1990) and blood-derived cells, probably also contribute to the process of axonal regeneration in fish. Microglia and phagocytes, for instance, produce factors which stimulate microglial cells (Guilian et al., 1993) and fibroblasts (Nathan, 1987). Schwann cells provide nerve growth factor to severed axons upon microglia stimulation in injured peripheral nerves (Heumann et al., 1987). Comparable signaling cascades and growth factor release may also take place in fish optic nerves (Boulis et al., 1993; Schwalb et al., 1994). However, the $100 \%$ survival of fish retinal ganglion cells after transection of the optic nerve and the subsequent massive regrowth of their axons provide evidence that intrinsic properties of these neurons are superior to those of mammals with regard to regeneration and growth.

\section{ACKNOWLEDGMENTS}

The authors thank Dr. Martin Bastmeyer for his continuous help with the immunostaining procedures, Ulrike Binkle for technical assistance, and Gisela Musial for printing the electron micrographs. This work was supported by grants of the Deutsche Forschungsgemeinschaft, SFB 156, TP C6 to C.A.O. Stuermer.

\section{LITERATURE CITED}

Baehr, M., C. Przyrembel, and M. Bastmeyer (1995) Astrocytes from adult rat optic nerves are non-permissive for regenerating retinal ganglion cell axons. J. Exp. Neurol. 131:211-220.

Bastmeyer, M., B. Schloßhauer, and C.A.O. Stuermer (1990) The spatiotemporal distribution of NCAM in the retinotectal pathway of adult goldfish detected with the monoclonal antibody D 3. Development 108:299-311.

Bastmeyer, M., M. Beckmann, M.E. Schwab, and C.A.O. Stuermer (1991) Growth of goldfish regenerating axons is inhibited by rat oligodendrocytes and CNS myelin but not by goldfish optic nerve/tract oligodendrocytes and fish CNS myelin. J. Neurosci. 11:626-640.

Bastmeyer, M., M. Bähr, and C.A.O. Stuermer (1993) Fish optic nerve oligodendrocytes support axonal regeneration of fish and mammalian retinal ganglion cells. Glia $8: 1-11$.

Bastmeyer, M. G. Jeserich and C.A.O. Stuermer (1994) Similarities and differences between fish optic nerve/tract oligodendrocytes and Schwann cells. Glia $22: 300-314$

Battisti, W.P., Y. Shinar, M. Schwartz, P. Levitt, and M. Murray (1992 Temporal and spatial patterns of laminin, chondroitin sulfate proteogly can and HNK-1 immunoreactivity during regeneration in the goldfish optic nerve. J. Neurocytol. 21:557-573.

Blaugrund, E., V. Lavie, 1. Cohen, A. Solomon, D.J. Schreyer, and M Schwartz (1993) Axonal regeneration is associated with glial migration comparison between the injured optic nerves of fish and rats. J. Comp Neurol. 330:105-112

Boulis, N.M., J. Winickoff, N. Irwin, M.F. Gu, D.-F, Chen, H. Zanjani, G.E. Schneider, and L.1. Benowitz (1993) Endogenous trophic factors involved in regeneration of the goldfish optic nerve. Soc. Neurosci. Abstr. 19:55.

Bovolenta, P., F. Wandosell and M. Nieto-Sampedro (1992) Central neurite outgrowth over glial scar tissue in vitro. In P.C. Letourneau, S.B. Kater, and E.R. Macagno (eds): The Nerve Growth Cone. New York: Raven Press, pp. 477-488.
Carbonetto, S., D. Evans, and P. Cochard (1987) Nerve fiber growth in culture on tissue substrata from central and peripheral nervous systems. J. Neurosci. 7:610-620.

Chamak, B., Morandi, V., and M. Mallat (1994) Brain macrophages stimulate neurite growth and regeneration by secreting thrombospondin. J. Neurosci. Res. 38:221-233.

David, S., C. Bouchard, O. Tsatas, and N. Giftochristos (1990) Macrophage can modify the nonpermissive nature of the adult mammalian central nervous system. Neuron 5:463-469.

Easter, S.S. (1987) Retinal axons and the basal lamina In J.R. Wolf, J. Sievers, and M. Berry (eds): Mesenchymal-Epithelial lnteractions in Neural Development. NATO ASl Series, Vol. H5. Berlin: SpringerVerlag, pp. 385-396.

Easter, S.S., B. Bratton, and S.S. Scherer (1984) Growth-related order of the retinal fiber layer in goldfish. J. Neurosci. 8:2173-2190.

Gaze, R.M. (1970) The Formation of Nerve Cell Connections. ed. London: Academic Press.

Giordano, S., E. Glasgow, P. Tesser, and N. Schechter (1989) A type II keratin is expressed in glial cells of the goldfish visual pathway. Neuron 2: 1507-1516.

Giordano, S., C. Hall, W. Quitschke, E. Glasgow, and N. Schechter (1990) Keratin 8 of simple epithelia is expressed in glia of the goldfish nervous system. Differentiation 44:163-172

Guilian, D., K. Vaca, and M. Corpuz (1993) Brain glia release factors with opposing action upon neuronal survival. J. Neurosci. 13:29-37.

Heumann, R., D. Lindholm, C. Bandtlow, M. Meyer, M.J. Radeke, T.P. Misko, E. Shooter, and H. Thoenen (1987) Differential regulation of mRNA encoding nerve growth factor and its receptor in rat sciatic nerve during development, degeneration, and regeneration: role of macrophages. Proc. Natl. Acad. Sci. U.S.A. 84:8735-8739.

Hirsch, S., M.A. Cahill, and C.A.O. Stuermer (1994) Fibroblasts repopulate the lesion after transection of goldfish optic nerves and are permissive substrates for regenerating retinal axons. In N. Elsner and H. Breer (eds): Proceedings of the 22nd Göttingen Neurobiology Conference, Vol. 11. Abstr. 136, 1994. Stuttgart: Thieme Verlag.

Hopkins, J.M., T.S. Ford-Holevinski, J.P. McCoy, and B.S. Agranoff (1985) Laminin and optic nerve regeneration in the goldfish. J. Neurosci 5:3030-3038

Jeserich, G., and T. Rauen (1990) Cell cultures enriched in oligodendrocytes from: the central nervous system of trout in terms of phenotypic expression exhibit parallels with cultured rat Schwann cells. Glia 3:65-74.

Johnson, A.R. (1993) Contact inhibition in the failure of mammalian CNS axonal regeneration. Bioessays 15:807-813.

Lanners, H.N., and B. Grafstein (1980) Early stages of axonal regeneration in the goldfish optic tract: an electron microscopic study. J. Neurocytol. 9:733-751

Levine, R.L. (1989) Organization of astrocytes in the visual pathways of the goldfish: an immunohistochemical study. J. Comp. Neurol. 285:231-245.

Levine, R.L. (1991) Gliosis during optic fiber regeneration in the goldfish: an immunohistochemical study. J. Comp. Neurol. 312:549-560.

Levine, R.L. (1993) Axon dependent glial changes during optic fiber regeneration in the goldfish. J. Comp. Neurol. 333:543-553.

Lowenger, E., and R.L. Levine (1988) Studies of the early stages of optic axon regeneration in the goldfish. J. Comp. Neurol. 271:319-330.

Luizzi, F.J., and R.J. Lasek (1987) Astrocytes block axonal regeneration in mammals by activating the physiological stop pathway. Science $237: 642-$ 645.

Maggs, A., and J. Scholes (1986) Glial domains and nerve fiber patterns in the fish retinotectal pathway. J. Neurosci. 6:424-438.

Maggs, A., and J. Scholes (1990) Reticular astrocytes in the fish optic nerve: macroglia with epithelial characteristics form an axially repeated lacework pattern, to which nodes of ranvier are apposed. J. Neurosei. 10:1600-1614

Markl, J and W W Franke (1988) Localization of cytokeratins in tissues of the rainbow trout: fundamental differences in expression pattern between fish and higher vertebrates. Differentiation 39:97-122.

McKeon, R.J., R.C. Schreiber, J.S. Rudge, and J. Silver (1991) Detection of neurite outorowth in a model of glial scarring following injury is correlated with the expression of inhibitory molecules on reactive astrocytes. J. Neurosci. 11:3398-3411.

Murray, M. (1982) A quantitative study of regenerative sprouting by optic axons in goldfish. J. Comp. Neurol. 209:352-362.

Nathan, C.F. (1987) Secretory products of macrophages. J. Clin. Invest 79.319-326. 
Nona, S.N., S.A.S. Shehab, C.A. Stafford, and J.R. Cronly-Dillon (1989) Glial fibrillary acidic protein (GFAP) from goldfish: its localisation in the visual pathway. Glia $2: 189-200$.

Nona, S.N., C.A. Stafford, A. Duncan, J.R. Cronly-Dillon, and J. Scholes (1994) Myelin repair by Schwann cells in the regenerating visual pathway: regional patterns revealed by X-irradiation. J. Neurocytol. 23:400-409.

Paschke, K.A., F. Lottspeich, and C.A.O. Stuermer (1992) Neurolin, a cell surface glycoprotein on growing retinal axons in the goldfish visual system is re-expressed during retinal axonal regeneration. J. Cell Biol. 117:863-875.

Peters, A., S.L. Palay, and H.D.E.F. Webster (eds.) (1991) The Fine Structure of the Nervous System. New York: Oxford University Press.

Reier, P.J. (1986) Gliosis following CNS injury: The anatomy of astrocytic scars and their influences on axonal regeneration. In $\mathrm{S}$. Fedoroff and $\mathrm{A}$. Vernadakis (eds): Astrocytes, Vol. 3. London: Academic Press, pp. 263-324.

Reier, P.J., and J.D. Houle (1988) The glial scar: Its bearing on axonal elongation and transplantation approaches to CNS repair. In S.G. Waxman (ed): Advances in Neurology: Functional Recovery in Neurological Diseases. New York: Raven, pp. 87-138.

Reynolds, E.S. (1963) The use of lead citrate at high $\mathrm{pH}$ as an electronopaque stain in electron microscopy. J. Cell Biol. 17:208-213.

Rhodin, J.A.G. (ed.) (1977) Histology. New York: Oxford University Press.

Richardson, K.C., L. Jarett, and E.H. Finke (1960) Embedding in epoxy resins for ultrathin sectioning in electron microscopy. Stain Technol. 35:313-323

Rudge, J.S., and J. Silver (1990) Inhibition of neurite outgrowth on astroglial scars in vitro. J. Neurosci. 10:3594-3603.

Scherer, S.S., and S.S. Easter (1984) Degenerative and regenerative changes in the trochlear nerve of goldfish. J. Neurocytol. 13:519-565.

Schwab, M.E., J.P. Kapfhammer, and C.E. Bandtlow (1993) Inhibitors of neurite growth. Annu. Rev. Neurosci. 16:565-595.

Schwalb, J.M., N.M. Boulis, M.-F. Gu, N. Irwin, and L.J. Benowitz (1994)
Characterization of two endogenous trophic factors involved in regeneration of the goldfish optic nerve. Soc. Neurosci. Abstr. 20:1325.

Sharma, S.C., A.G. Jodhao, and P.O. Prasado Rao (1993) Regeneration of supra-spinal projection neurons in the adult goldfish. Brain Res. 620:221228

Skene, J.P.H. (1989) Axonal growth-associated proteins. Annu. Rev. Neurosci. 12:127-156.

Sommer, J., and M. Schachner (1981) Monoclonal antibodies (O1 to O4) to oligodendrocyte cell surfaces: an immunocytochemical study in the central nervous system. Dev. Biol. 83:311-327.

Stafford, C.A., S.A.S. Shehab, S.N. Nona, and J.R. Cronly-Dillon (1990) Expression of glial fibrillary acidic protein (GFAP) in goldfish optic nerve following injury. Glia 3:33-42.

Strobel, G.. and C.A.O. Stuermer (1994) Growth cones of regenerating retinal axons contact a variety of cellular profiles in the transected goldfish optic nerve. J. Comp. Neurol, 346:435-448.

Stuermer, C.A.O., and S.S. Easter (1984) A comparison of the normal and regenerated retinotectal pathway of goldfish. J. Comp. Neurol. 223:5776.

Stuermer, C.A.O., M. Bastmeyer, M. Bähr, G. Strobel, and K. Paschke (1992) Trying to understand axonal regeneration in the CNS of fish. $J$. Neurobiol. 23:537-550.

Towbin, H. T. Staehlin, and J. Gordon (1979) Electrophoreticitransfer of proteins from polyacrylamide gels to nitrocellulose sheets: procedure and some applications. Proc. Natl. Acad. Sci. U.S.A. 76:4350-4354. '

Vanselow J. M E Schwab, and S. Thanos (1990) Responses of regenerating rat retinal ganglion cell axons to contacts with central nervous system myelin in vitro. Eur. J. Neurosci. 2:121-125.

Vielmetter, J B. Stolze, F. Bonhoeffer, and C.A. O. Stuermer (1990) In vivo assay to test differential substrate affinities of growing axons and migratory cells. Exp. Brain Res. 81:283-287.

Vielmetter J F. Lottspeich, and C.A.O. Stuermer (1991) The monoclona antibody E 587 recognizes growing (new and regenerating) retinal axons in the goldfish retinotectal pathway. J. Neurosci. 11:3581-3593. 